\title{
AVULSÃO DENTÁRIA TRAUMÁTICA ACIDENTAL: CUIDADOS ODONTOLÓGICOS PARA O REIMPLANTE
}

TRAUMATIC ACCIDENTAL TEETH AVULSION: DENTAL CARE

FOR REIMPLANTATION

Adielson Castro Siqueira
Patrícia Elaine Gonçalves

Resumo

Avulsão do dente permanente é a completa retirada do dente do alvéolo de origem. Percebe-se que ela se tornou um problema de saúde pública, pois apresenta alta prevalência, por falta de conhecimento da população no preparo em lidar com ela, assim como profissionais da área de saúde, inclusive da odontologia. Contudo, existe um protocolo padronizado que deve ser divulgado desde os procedimentos de pré e pós-tratamento do dente avulsionado, possibilitando um bom prognóstico. Conclui-se que, para obter-se sucesso no tratamento da avulsão dentária, deve ser seguido o protocolo já recomendado, além da capacitação dos educadores, médicos, enfermeiros, cirurgiões-dentistas quanto aos primeiros procedimentos para que o prognóstico tenha um desfecho favorável, ou seja, desde a conservação do dente avulsionado e seu tratamento específico.

Palavras-chave: Odontologia; AVULSÃO DENTÁRIA; ODONTOLOGIA PREVENTIVA.

\author{
Cirurgião-dentista graduado pelo \\ Centro Universitário UnirG \\ Cirurgiã-dentista e Profa. Colaboradora da Faculdade de \\ Odontologia - Universidade Nove de Julho - UNINOVE.
}

\begin{abstract}
Avulsion of the permanent tooth is a full withdrawal from the tooth socket of the home. We find that has become a public health problem, because shows a high prevalence, the population is not aware and prepared to deal with it, as well as professionals in the health area, including the dentistry. However, there is a standardized protocol that is the need to disclose it since the procedures for pre and post treatment in the tooth socket, allowing a good prognosis. Concluded to achieve success in the treatment of dental avulsion must follow a protocol and should be training of educators, doctors, nurses, surgeons dentists, as the first procedures for the prognosis of dental treatment is favorable, on the preservation of avulsion tooth and specific their treatment.
\end{abstract}

Keywords: DenTISTRY; TOOTH AVULSION; PREVENTIVE DENTISTRY. 


\section{INTRODUÇÃO}

A avulsão dentária é a completa retirada do dente do alvéolo de origem. Histologicamente, as estruturas que podem ser afetadas em uma avulsão são: polpa, ligamento periodontal, cemento e osso alveolar.

O prognóstico do elemento dentário avulsionado depende da qualidade do atendimento, no ato do trauma, além de uma análise criteriosa de fatores, como a idade do paciente, a área traumatizada, o tecido de suporte afetado, tempo que o dente permanece fora do alvéolo, e a sua risogênese. Diante disso, Prado e Salim ${ }^{1}$ ressaltam a importância dessa análise, e o manejo dos procedimentos executados durante uma urgência resultará em maiores chances de sucesso no prognóstico. Assim, a atenção odontológica frente à avulsão dentária consiste no reimplante imediato. Já o tratamento endodôntico deve ser realizado de forma radical, associado ao tratamento terapêutico, depois de uma análise criteriosa dos fatores já citados.

O reimplante imediato deve ocorrer para que seja possível a recuperação das funções do dente, pois as células e fibras do ligamento periodontal são responsáveis pela integridade radicular e inserção da raiz dentro do osso alveolar. Por isso é que se dá tanta importância quanto à rapidez de colocar o dente no alvéolo, e se não for possível, o mesmo deve ser conservado para manter a vitalidade do ligamento periodontal e do próprio dente, em meio aquoso, como a saliva.

O objetivo do trabalho foi realizar uma revisão da literatura odontológica acerca da atenção odontológica frente à avulsão dentária de dentes permanentes.

\section{ReVisão de Literatura}

\section{EPIDEMIOLOGIA}

Segundo Guedes-Pinto, ${ }^{2}$ a avulsão dentária representa aproximadamente $15 \%$ das lesões traumáticas na dentição permanente, ocorrendo com mais frequência em pacientes de 7 aos 11 anos de idade. A estrutura frouxa do ligamento periodontal e a alta resistência do tecido ósseo que circunda os dentes em erupção favorecem a avulsão dental.

Sottovia et al. ${ }^{3}$ narram que a maior prevalência de avulsão dentária de dente permanente ocorre no sexo masculino, principalmente, na idade de 5 a 15 anos, sendo que a maioria dos incidentes ocorre no mês de férias (72\%), durante atividades desportivas e recreativas (39\%), quedas e acidentes $(33 \%)$, violência interpessoal $(15 \%)$, aciden- te rodoviário (7\%). Já Bruns e Perinpanayagan ${ }^{4}$ mencionam que os dentes mais acometidos nas atividades desportivas e recreativas são os incisivos centrais e laterais.

Bittencourt et al. ${ }^{5}$ avaliaram a conduta de professores diante de uma situação de urgência de avulsão dental, já que passam mais tempo com as crianças. De 160 entrevistados, apenas 21,9\% deles reposicionariam o dente no alvéolo, destes, $52,2 \%$ replantariam imediatamente, enquanto $42,8 \%$, só após consultar os pais ou o cirurgião-dentista. Já aqueles que não reposicionariam o dente no alvéolo, $26,4 \%$ armazenariam em um recipiente vazio; $20 \%$ com água; $12 \%$ jogariam o dente fora; e apenas $0,8 \%$ colocariam o dente na saliva.

Al-Asfour et al. ${ }^{6}$ realizaram uma curta palestra sobre avulsão dentária, e averiguaram o conhecimento adquirido por meio da mesma. Dos 43 participantes, depois da execução da palestra, observou-se que o conhecimento melhorou a respeito do dente reimplantado de $8 \%$ para $93 \%$, sobre a avulsão dos dentes permanentes. Já com relação à importância do tratamento do dente extra-alveolar foi de $4 \%$ para $86 \%$, principalmente sobre seu armazenamento adequado.

\section{CONSERVAÇÃo E ARMAZENAMENTO DO DENTE AVULSIONADO}

Guedes-Pinto ${ }^{2}$ relata que o sucesso do procedimento de reimplantes está relacionado ao período passado entre a perda do dente e sua reposição no alvéolo. A condição do dente e, particularmente, a condição do tecido do ligamento periodontal remanescente na superfície radicular são fatores importantes que influenciam o sucesso do reimplante.

Por isso, se a avulsão dentária ocorreu em um ambiente limpo, o dente deve ficar imerso em soro fisiológico e a superfície radicular não deve receber nenhum tratamento mecânico ou químico, ou seja, deve ser apenas reimplantado. Contudo, se o dente estiver sujo, deve-se tentar limpar a superfície radicular, mas é muito importante preservar quaisquer remanescentes do ligamento periodontal que ainda estejam aderidos à raiz. Portanto, os pais precisam ser instruídos a manter o dente imerso em um meio adequado e trazer a criança e o dente para cuidados odontológicos imediatos. ${ }^{2}$ Porém, Shashikiran et al. ${ }^{7}$ observaram a negligência dos pais em como se limpar o dente, como se limpar o alvéolo, como conservar o dente para procurar um serviço de urgência, a incerteza e desconhecimento de que o dente poderia ser reimplantado e suas possíveis 
complicações, o uso de antibiótico e terapias pré e pós-procedimento.

De acordo com Guedes-Pinto ${ }^{2}$ e Mc Donald e Avery, ${ }^{8}$ a saliva humana é um líquido de armazenagem aceitável de curto prazo, pois a saliva do paciente estará prontamente disponível para ser coletada em um pequeno recipiente (ou na mão em concha) para manter o dente úmido, enquanto for transportado até o consultório odontológico. Embora a água de torneira seja uma solução de armazenamento comumente recomendada (e seu uso será preferível a deixar o dente se desidratar). Mas, nem a água nem a saliva são tão boas como o leite ou a solução salina, se o dente precisar ser armazenado por um longo período (mais de 30 minutos).

\section{TRATAMENTO}

O paciente deve receber atenção imediata quando chegar ao consultório. Se o dente ainda não tiver sido reimplantado, o dentista deve se esforçar para minimizar o tempo adicional que o dente fica fora do alvéolo. O estado geral do paciente precisa ser rapidamente avaliado, para confirmar se não existem danos pessoais com maior prioridade. Além disso, deve-se realizar exame clínico e radiográfico da região a fim de detectar objetos estranhos. ${ }^{2}$

Segundo McDonald e Avery $^{8}$ e Guedes-Pinto, ${ }^{2}$ existem poucos relatos na literatura que mostram o sucesso dessa técnica por períodos indefinidos. Entretanto, uma reabsorção radicular lenta ou mesmo rápida ocorre até mesmo com a técnica mais precisa e cuidadosa. O reimplante de dentes permanentes, entretanto, é indicado e recomendado, porque em muitos casos se consegue uma retenção prolongada, especialmente quando ocorre logo após o acidente. Além do que, o dente reimplantado serve como um mantenedor de espaço e guia para os dentes adjacentes, principalmente se ocorrer durante o período transitório da dentição'. Ademais, os autores mencionam os passos a serem seguidos para o reimplante, que são: a lavagem suave do dente e do alvéolo por irrigação, exame radiográfico da área traumatizada, na busca de eventuais fraturas do rebordo alveolar e o reposicionamento imediato do dente sem anestesia local. Muitas vezes, porém, o reimplante pode ser dificultado pela presença de coágulo sanguíneo no alvéolo dental, o qual deve ser removido após a anestesia do paciente, por meio de irrigação e aspiração com o soro fisiológico e curetas, sem, contudo, raspar as paredes do alvéolo e utilizar a pressão digital para mantê-lo em posição e realizar a avaliação radiográfica. ${ }^{10}$
O procedimento de reimplante também tem um valor psicológico. Ele propicia à criança e aos pais esperança de sucesso; embora seja informado sobre a possibilidade da perda eventual do dente, minimizando o impacto emocional do acidente. ${ }^{8}$

Lopez-Marcos et al. ${ }^{10}$ mencionam que o tratamento dos dentes permanentes avulsionados que serão reimplantados devem seguir um protocolo, ou seja, o dente deve ser segurado pela coroa e não pela raiz, evitando danificar o ligamento periodontal remanescente. Para o caso em que o trauma foi até uma hora, deve-se imergir o dente em uma solução de fluoreto de sódio por 5 minutos. Já, quando o tempo de exposição for maior que uma hora, deve-se limpar a superfície da raiz com água e soro salino e inserir o dente em uma solução de doxiciclina (100mg/20 ml solução salina). Essa solução poderá ser útil mais tarde na prevenção da reabsorção radicular externa. Após o reimplante, devem ser tomadas as possíveis medidas cabíveis para o tratamento adequado, como a estabilização, por meio de esplintagem ou tala.

\section{ESPLINTAGEM}

Segundo Guedes-Pinto, ${ }^{2}$ após o reimplante do dente avulsionado, há a necessidade de um esplinte, ou contenção, para estabilizá-lo durante, no mínimo, a primeira semana de cicatrização. Porém, essa só será aceitável, se atender aos seguintes critérios: ser fácil de fabricar diretamente na boca, sem procedimentos laboratoriais demorados; ser colocada passivamente, sem forçar os dentes; não tocar os tecidos gengivais, causando irritação; não interferir com a oclusão normal; ser facilmente limpa e permitir a higiene oral adequada; não traumatizar os dentes ou a gengiva durante a aplicação; permitir o acesso para terapia endodôntica; ser facilmente removida. Deve também permitir uma mobilidade ao dente reimplantado compatível à mobilidade normal do dente. A estabilização rígida é caracterizada prejudicial ao reparo adequado do ligamento periodontal.

A contenção com resina adesiva e fio ortodôntico é a mais indicada, já que pode ser usada na maioria das situações que requer a estabilização de um ou mais dentes, se houver dentes saudáveis suficientes para a ancoragem. O fio ortodôntico retangular ou redondo é manipulado para aproximar-se da configuração aproximada do arco, junto à porção média das superfícies labiais dos dentes a serem incorporados ao esplinte. Inclui-se, pelo menos, um dente sadio de cada lado do dente a ser estabilizado. O método atu- 
almente utilizado para a contenção é o da resina composta fotopolomerizável, com o fio de nylon para dar certa mobilidade ao dente. Essa mobilidade permite a reorganização mais rápida das fibras, caracterizando a contenção fisiológica. A técnica consiste no ataque ácido da região vestibular dos dentes reimplantados e de, pelo menos, um dente sadio adjacente a ele. Segue-se, então, a adaptação de um fio de nylon $n$. 70 nesse dente, que será fixado por resina. A porção de resina será de aproximadamente $4 \mathrm{~mm}$, que deve cobrir completamente o fio, sem invadir os contatos interproximais e a região cervical dos dentes. Após uma semana, o epitélio gengival é readaptado na junção cemento-esmalte. Dez a quatorze dias após, já se observa a reinserção das fibras periodontais entre o cemento e o osso alveolar., ${ }^{2,8}$

Entretanto, o paciente deve ser aconselhado a não morder diretamente sobre o dente reimplantado por três a quatro semanas após o trauma e, a seguir, gradualmente iniciar a função, normalmente. Durante esse período, o alimento deve ser picado em pedaços pequenos e mastigado cuidadosamente com os dentes não afetados. O paciente deve manter boa higiene oral, escovando os dentes e usando o fio dental normalmente, além de usar bochechos com clorexidina para eliminação da placa bacteriana., ${ }^{2,8}$

\section{TRATAMENTO ENDODÔNTICO}

Todos os dentes permanentes reimplantados com desenvolvimento apical completo devem ser submetidos à pulpectomia, logo após o reimplante, independentemente do tempo que o dente ficou fora da boca. Embora existam alguns relatos de revitalização, porém são remotos.

Guedes-Pinto $^{2}$ menciona que o tratamento endodôntico não deve ser realizado antes do reimplante para não aumentar o tempo extra-alveolar, a menos que o dente já tenha sofrido ressecamento, ou o paciente se apresenta no consultório após duas horas do acidente, e tenha sido armazenado em condições impróprias. Nesses casos, deve-se tratar a superfície radicular com fluoreto de sódio a $2,4 \%(\mathrm{pH}=5,5)$ por minutos, obturar o canal e reimplantá-lo, realizando contenção rígida que permanecerá por 45 dias.

O material de hidróxido de cálcio deve ser usado para obturar o canal radicular, e deve ser substituído a cada três a seis meses, até que se decida obturar o canal com guta-percha. A duração ideal do tratamento com hidróxido de cálcio é desconhecida, mas geralmente o hidróxido de cálcio deve ser mantido no canal por, no mínimo, seis meses, ou até que ocorra o fechamento da extremidade radicular (tampão apical), quando o dente apresenta rizogênese incompleta. ${ }^{8}$

\section{TERAPÊUTICA MEDICAMENTOSA}

Quanto à terapia medicamentosa, Pozo et al. ${ }^{11}$ descrevem que no caso de dentes avulsionados, aplica-se antibiótico local no dente, porém administra-se antibiótico sistêmico quando o paciente apresenta comprometimento sistêmico, como problemas cardíacos associados com endocardite, cateteres vasculares, dispositivos protéticos, nos quais se realiza antibioticoprofilaxia previamente. Os antibióticos devem ser administrados oralmente e a indicação é a penicilina $\mathrm{V}$ associada ao ácido clavulânico. Em caso de alergia, a alternativa é a clindamicina. A terapia deve prosseguir por, no mínimo, uma semana após o reimplante. Se o ápice estiver fechado, o prolongamento da terapia antibiótica será até que a polpa seja extirpada. ${ }^{8}$

\section{OUTROS TRATAMENTOS}

Nuzzolese et al. ${ }^{12}$ mencionam que outro tipo de tratamento para a avulsão traumática é o implante dentário de carga imediata. Porém, na região anterior da maxila em uma avulsão dentária traumática pode se revelar útil, apesar do incompleto desenvolvimento esquelético e possivelmente mudanças que irão ocorrer no tecido circundante do implante suplementado para evitar a contração do tecido mole, reabsorção óssea alveolar, e apresenta uma resposta positiva estética e psicológica.

Outro material testado em rato foi a solução de nitrato de gálio com finalidade de inibir a reabsorção, com curativo intracanal para dentes reimplantados tardiamente. Os resultados observados foram que a solução de nitrato de gálio e a pasta de hidróxido de cálcio diminuíram a reabsorção radicular, mas não evitaram a sua ocorrência, ou seja, ambos têm ações iguais. ${ }^{13}$

\section{Prognóstico}

Shashikiran et al. ${ }^{7}$ relatam que o prognóstico final de uma avulsão dentária traumática depende do conhecimento do processo e etapas de tratamento, já que a maioria das lesões traumáticas ocorre na escola e em casa, ou seja, nem todos os pais e professores estão habituados ou sensibilizados para atuar diante dessa urgência. Assim, quanto mais cedo um dente puder ser reimplantado em seu alvéolo após a avulsão, tanto melhor será o prognóstico de permanência sem reabsorção radicular e se o dente tiver estado fora da boca por 
menos de 30 minutos, o prognóstico é, portanto, mais favorável. ${ }^{8}$

Martins et al. ${ }^{14}$ realizaram tratamento endodôntico dos dentes 41 e 42 em ambiente extraoral após avulsão dental, e obturaram o canal com guta-percha e tratamento do exterior da raiz superficialmente com solução de fluoreto de sódio ( $2 \%)$ e em seguida foram reimplantados e imobilizados (splintagem). Após o primeiro ano, foi observada uma progressiva reabsorção externa dos dentes e, no terceiro ano, os reimplantes dos dentes foram perdidos pela quase reabsorção total da raiz.

\section{Material e Métodos}

O estudo consiste na revisão de literatura sobre o tema estudado. Essa prática consiste num processo de levantamento e análise do que já foi publicado sobre o tema em análise, que segundo Noronha e Ferreira ${ }^{15}$ essa metodologia consiste em uma análise da produção bibliográfica em determinada área temática, fornecendo uma visão geral, evidenciando novas ideias.

Para isso, realizou-se a coleta de trabalhos científicos sobre o assunto em bancos de dados internacionais e nacionais a respeito de estudos odontológicos como: PUBMED (www.pubmed. com), SCIELO (www.scielo.org), BBO, MEDILINE e LILACS (www.bireme.br). Utilizaram-se palavras-chave como "avulsão", "prevenção", "tratamento", "odontologia" "trauma dental", podendo ser colocados isolados ou em conjunto.

\section{Discussão}

Percebe-se a necessidade de capacitação de professores, pais e familiares para que os mesmos se sintam seguros para realizar as intervenções inéditas e imediatas em casos de avulsão dentária traumática acidental e favorecendo o prognóstico. O fato é que a sociedade, em grande parte, é desconhecedora das possíveis consequências que poderão ocorrer, mesmo se o dente avulsionado for reimplantado ou não., 5

Diversos autores ${ }^{2,8,9,16}$ mencionam a necessidade de se realizar um tratamento de emergência de um dente avulsionado em pequeno espaço de tempo, com um tratamento multidisciplinar. Tais condutas requerem conhecimento e cuidado a serem tomados, e nem em todos os casos as vítimas têm o conhecimento ou sabem de sua importância. A divulgação aos profissionais responsáveis pelos tratamentos destas lesões por meio de campanhas de divulgação pública sobre o correto procedimento pré e pós-trauma para que possa estabelecer a melhor estratégia de tratamento, portanto, se faz absolutamente necessária. $2,5,8,10$ Considere-se, assim, que a educação e informação devem ser direcionadas tanto aos profissionais quanto à população em geral. ${ }^{5,8}$

A primeira conduta que deve ser passada à população seria a de manter a viabilidade das células do ligamento periodontal que permanecem presas à porção radicular, por meio da informação pública. A realização do reimplante nos primeiros 30 minutos, ou o acometimento em meio de transporte como deveria ser, deve ser informada a professores da educação, orientadores desportistas, médicos, enfermeiros, entre outros profissionais. O segundo objetivo é interagir para possibilitar a revascularização do tecido pulpar, caso a vascularização da polpa não aconteça, deve-se evitar a contaminação do canal radicular, pois o tecido necrótico é extremamente susceptível a infecções., ${ }^{2,7-10}$

Ademais, deve-se segurar o dente pela coroa, tentando não tocar na raiz. Enxágue o dente com a saliva do paciente, água filtrada ou solução salina, em seguida recoloque o dente no local onde estava, e imediatamente vá ao dentista. Caso o paciente não consiga reposicionar o dente, deve guardá-lo no fundo do vestíbulo bucal, prevenindo para que não engula ou aspire. Se for impossível manter o dente na boca, pode-se colocar o dente em um recipiente com leite ou solução salina balanceada $(2 \%))^{2,8,9,17}$

Quando o paciente chega ao consultório, o dentista deve fazer uma análise do dente para decidir se o mesmo pode ser salvo independente se já foi reimplantado ou não. Deve-se observar radiograficamente o dente para verificar se está na posição correta, e logo após imobilizá-lo por sete a dez dias. O dispositivo de imobilização deve ser todo higiênico quanto possível e posicionado longe da gengiva marginal e da raiz dentária. Durante a cicatrização, é preciso controlar o processo inflamatório ao mínimo possível, para que não haja a reabsorção inflamatória da raiz. A estabilidade aplicada ao dente não é necessariamente rígida, pois pode predispor a uma anquilose. Os movimentos fisiológicos dos dentes são indicados por alguns para promover união fibrosa desejada., 2,8,9,17

Período extra-alveolar maior que duas horas apresenta pouco sucesso ao tratamento, já até 30 minutos o resultado é excelente. Ademais, alguns fatores devem ser adotados antes do reimplante, como: o dente avulsionado não deve ter doença periodontal avançada, o alvéolo precisa estar razoavelmente íntegro para reposicionar o dente avulsionado, não 
pode ter nenhuma contraindicação ortodôntica, como apinhamento dentário significativo. ${ }^{17}$

Salienta-se que não é necessário remover todo coágulo sanguíneo de dentro do seu alvéolo, deve ser feita uma limpeza cuidadosa com solução salina (2\%) estéril removendo a parte do coágulo, e nunca raspar a superfície radicular do dente e o alvéolo dentário evitando a destruição do tecido periodontail. Quando o dente passar mais de $30 \mathrm{mi}-$ nutos avulsionado, a desinfecção do dente deve ser feita cuidadosamente com doxiciclina $(100 \mathrm{mg} / 20$ ml solução salina) por 5 minutos. A solução salina $(2 \%)$ tem um parecer de reduzir a incidência da anquilose por melhorar a sobrevivência das células periodontais da superfície radicular, também ajuda a remover os debris da raiz e eliminar as bactérias. A doxiciclina inibe as bactérias do lúmen pulpar, assim diminuindo o maior obstáculo à revascularização. Medicação terapêutica, como anti-inflamatório, deve ser administrada e também antimicrobiana. A alimentação não deve causar nenhuma injúria aos tecidos de suporte, havendo restrição de alimentos duros e pegajosos. , $^{2,9,17}$

\section{Conclusões}

Para obter-se sucesso no tratamento da avulsão dentária traumática acidental deve ser seguido um protocolo já recomendado, e o mesmo deve ser divulgado a fim de promover informação e capacitação aos educadores, médicos, enfermeiros, cirurgiões-dentistas e à população, em geral, quanto aos primeiros procedimentos para o prognóstico ser favorável, ou seja, desde a conservação do dente avulsionado até a finalização do seu tratamento específico.

\section{REFERÊNCIAS BIBLIOGRÁFICAS}

1. Garcia-Ballesta C, Pérez Haranjarin L, Cortés-Hillo O. Alteraciones radiculares en las lesiones traumáticas del ligamento periodontal. RCOE 2003; 8(2):197-208.

2. Guedes-Pinto AC. (org.). Reabilitação bucal em odontopediatria: atendimento integral. São Paulo: Santos Livraria Editora; 1999.

3. Sottovia AD. Reimplante dentário tardio após o tratamento da superfície radicular com hipoclorito de sódio e fluoreto de sódio: análise histomorfométrica em ratos [Dissertação]. Araçatuba (SP): Universidade Estadual Paulista. Faculdade de Odontologia de Araçatuba; 2004.
4. Bruns T, Perinpanayagan H. Dental trauma that require fixation in a children's hospital. Dental Traumatol 2008; 24: 59-64.

5. Bittencourt AM, Pessoa OF, Sílvia JM. Avaliação do conhecimento de professores em relação ao manejo da avulsão dentária em crianças. Rev Odontol UNESP 2008; 37(1):15-9.

6. Al-Asfour A, Anderson L, Al-Jame Q. School teacher's knowledge of tooh avulsion and dental frist ain before and after receiving information about avulsed teeth and replantation. Dental Traumatol 2008; 24:43-9.

7. Shashikiran ND, Reddy VVS, Nagavenir NB. Knowledge and attitude of 2000 parents (verbam and rural -1.000 each) with regard to avulsed permanent incisors and their emergency management, in and around davangere. J Indian Soc Pedod Prev Dent 2006; 24(3):116-21.

8. McDonald RE, Avery Dr. Odontopediatria. 7a. ed. Rio de Janeiro: Guanabara Koogan; 2000.

9. Andreasen JO. Atlas de reimplante e transplante de dentes. São Paulo: Ed. Panamericana; 1994.

10. Lopez-Marcos JI, Garcia B, Valle SG. Tratamiento de las lesiones dentales traumáticas. Revisión bibliográfica actualizada. Acta Odontol Venez 2006; 44(3): 431-6.

11. Pozo PP, Soto MJB, Troisfontaines ESE. Antibiotic prophylaxia in pediatric odontology. Ana update. Med Oral Patol Oral Cir Bucal 2006; 11:352-7.

12. Nuzzolese E. Immediate Loading of Two Single Tooh Implants in the Maxilla: Preliminary Results After One Year. J Contemp Dental Practice 2005; 6(3): 148-57.

13. Mori GG, Garcia RB, Moraes IG, Bramate CM, Bernardineli N. Morphometric and microscopic evaluation of the effect of gallium nitrate as a root canal dressing in rat teeth submitted to late replantation. J Appl Oral Sci 2006; 14(6):405-9.

14. Martins WD, Westphalen FH, Westphalen VPD, Souza PHC. Multiple Dentoalveolar Traumatic Lesions: Report of a Case and Proposition of Dental Polytrauma as a New Term. J Contemp Dent Prac 2004; 5(4):139-47.

15. Noronha DP, Ferreira SMSP. Revisões de Literatura. In: Campello BS, Condon BV, Kremer JM. (org.). Fontes de informação para pesquisadores e profissionais. Belo Horizonte: UFMG; 2000. 
16. Prado R, Salim M. Cirurgia bucomaxilofacial: diagnóstico e tratamento. Rio de Janeiro: MEDSI; 2004.

17. Peterson JL, Ellis E, Hupp RJ, Tucker RM. Cirurgia oral e maxilo facial contemporânea. 3a. ed. Rio de Janeiro: Guanabara Koogan; 1998.

Submetido em: 6-5-2012

Aceito em: 5-7-2012 